\title{
Studies on Training Applied Technique-oriented Talent of Safety Engineering Profession
}

\author{
Huiping Liu \\ School of Urban Construction and Safety Engineering \\ Shanghai Institute of Technology \\ Shanghai 201418, China \\ E-mail address: huipingliu@ @oxmail.com \\ Peng Zhu \\ School of Urban Construction and Safety Engineering \\ Shanghai Institute of Technology \\ Shanghai 201418, China
}

\author{
Zhangrui Liu \\ School of Urban Construction and Safety Engineering \\ Shanghai Institute of Technology \\ Shanghai 201418, China \\ Daoliang Zhao \\ School of Urban Construction and Safety Engineering \\ Shanghai Institute of Technology \\ Shanghai 201418, China
}

\begin{abstract}
Under the background that the education of local institute should be changed from the regular higher education to the applied technique and vocational education, as proposed by China's Ministry of Education, according to the characteristics of the safety engineering discipline and the investigation results that made on some corresponding enterprises and public institutions in Shanghai, the problems and drawbacks existed in the talent training of safety engineering profession in Shanghai Institute of Technology (SIT) have been pointed out. Accordingly, the knowledge structure of safety engineering profession has been optimized, and new schemes of talent training and course setting have been proposed. At the same time, the reform measures on teaching process and construction of teaching resource have been raised. Through the study, the talent training of safety profession in SIT will be more targeted and better meet the need of economic and social development for talents with applied technique of safety profession in Shanghai.
\end{abstract}

Keywords-local institute; safety engineering profession; applied technique; talent training

\section{INTRODUCTION}

Higher education of safety engineering discipline in China has been developed and matured gradually in recent decades. Its application has been infiltrated every aspect of people's production and life, and played a vital role in ensuring the public's safety and health and in avoiding major and serious accidents. After entering the $21^{\text {st }}$ century, there were many production accidents occurred in China, and the economic loss caused by the safety accidents were up to 200 billion yuan per year[1]. The above hard reality forces the society to require more safety professionals and proposes higher standards for safety professionals. But in our nation, there are not uniform teaching requirement, clear standard and assessment method for safety technical personnel. At the same time, the talent training mode hasn't the single criteria, and also there are not high level teaching materials during the teaching process, which restrict the training of the students in safety engineering profession[2]. An investigation performed by the Teaching

Supported by the Teaching Research Project of Shanghai Institute of Technology (A26/4521ZK140007109) and Key Course Construction Project of Shanghai Institute of Technology (A22/33110M140041).
Guiding Committee for College Safety Engineering Profession under the Ministry of Education revealed that the qualities of safety professionals were not be readily adapted to the demand of the social development. The teaching aims of the safety profession should be oriented to the 21 st century, and it should be a liberal education which emphasizes both the safety management and techniques, combines extensive knowledge with profound knowledge[3]. In order to solve the above problems and realize the aims proposed by the Teaching Guiding Committee for College Safety Engineering Profession, a great deal of researches on the development of safety profession[4-5], textbook construction and educational reform of safety engineering[6-7] have been carried out, and has got certain achievements.

Under the background that the regular higher education of local universities should be transformed to the applied technologies and occupational education, which initiated by China's Ministry of Education, according to the characteristics of safety engineering discipline, the authors take the safety engineering profession of Shanghai Institute of Technology (SIT) as an example and discuss how to train the applied technique-oriented talent of safety profession according to the actual demand of safety professionals in Shanghai and the current education of safety engineering profession in SIT.

\section{CHARACTERISTICS OF SAFETY ENGINEERING DISCIPLINE AND DEMAND FOR APPLIED TECHNIQUE-ORIENTED TALENT OF SAFETY ENGINEERING PROFESSION IN SHANGHAI}

\section{A. Characteristics of Safety Engineering Discipline}

Safety engineering discipline is a new science emerged and developed gradually in recent decades. It has the characteristics of subject overlapping, comprehensiveness and practicality, and covers the disciplines such as art, science, engineering, law, management and medical science. Safety engineering is closely related with the basic theory of safety, and it is also closely combined with the engineering practice[8]. The security during the production activity must 
be realized by the detailed management measures and technologies. At the time of emphasizing the safety basic knowledge, safety engineering profession should pay more attention on training practical ability.

Additionally, the safety engineering discipline has certain unique industrial characteristics. Various industries require safety professionals with different knowledge structures[9]. So, in order to meet the need of the market and socioeconomic development, the teaching emphasis of safety engineering profession in various universities are different, which depend on the specialized characteristics and the regional environment of the university. For example, the safety engineering profession of the universities that are strong in the chemical technology (e.g.: Nanjing Technology University, Nanjing University of Science and Technology, East China University of Science and Technology, South China University of Technology, etc) put emphasis on training professionals of chemical safety; the safety engineering profession of the universities that are strong in the coal mines and mining (e.g.: China University of Mining \& Technology, Central South University, Hunan University of Science and Technology, etc) put emphasis on training talents of mine safety, and so on.

\section{B. Demand for applied technique-oriented talents of safety engineering profession in Shanghai}

As the centre of international economy, finance, business and shipping, Shanghai has great chemical industry, building enterprises, manufacturing industry and transportation industry. In order to learn about the demand for safety engineering professionals in Shanghai, the authors and colleagues conducted an intensive and comprehensive investigation in Shanghai city (country) Safety Supervision Bureau, construction companies and chemical industries. The results are as the following:

- The safety engineering professionals in Shanghai are in great demand. There are lots of large-scale chemical industry parks, construction companies, installation companies, ship builders and manufacturing enterprises in Shanghai, which has great demand for safety management personals and safety engineers. Although there are hundreds of safety engineering graduates work in Shanghai per year, the supply is still unable to meet the demand. No matter whether in the public institution such as the Safety Supervision Bureau or in the companies (especially the state-owned and the private enterprises), lots of their safety management professionals haven't safety engineering background and also haven't the professional qualities that must be possessed by the safety engineering. Hence, more safety engineering professionals are urgently required to replace those without safety engineering background.

- Need for the applied technique-oriented talents that not only have the solid safety foundation, but also have certain industrial basic knowledge and practical ability. During the investigation process, some leaders of the Safety Supervision Bureau said that the professional foundation knowledge of the safety law-executors were very bad, and their safety inspection work mainly depend on the experience. They will feel incompetent when the safety problem need be resolved with safety professional knowledge (especially the industrial specialized knowledge). In addition, although many graduates of safety engineering profession have been introduced to the enterprises, they can only perform their work normally after being trained for about 1-2 years, because they are lack of the corresponding industry foundation knowledge. So, the person in charge of the enterprises suggested that the students of safety engineering profession in SIT, in order to become the truly applied technique-oriented talents, should be trained to have certain practical ability and problem-solving ability in safety engineering.

- Owing to the industrial structures, Shanghai requires many applied technological talents and management staffs in construction safety, chemical safety, mechanical safety, electrical safety, traffic safety and fire-proof \& explosion proof.

\section{Problems Existing In TRAining TAlents OF SAFETY PROFESSION IN SIT}

As a local college, SIT has trained a lot of applied talents for various occupations. The safety profession in SIT has existed for about 40 years and it is the only one in Shanghai's universities for a long time. It has trained thousands of safety engineering professionals for society. In recent years, East China University of Science and Technology and Shanghai Maritime University had set the safety profession, which mainly focus on the chemical process \& equipment safety and ship \& port safety, respectively. According to the development of safety engineering profession in the above two universities and other domestic universities and combining with the investigation results, it can be found that the safety profession in SIT has the following problems and shortcomings:

- Lack of a definite self-positioning, so there are no specific features in talent training mode, curricula system construction and teaching process.

- Lack of practical teaching source, so the quality of practical teaching is not good, which restricts the training of the students' practical ability.

- The teachers of safety profession are lack of the engineering background and practical experience, which is unfavorable to train the students' practical skills and problem-solving ability.

\section{Study On TRAINING APPLIED TEChNIQUE-ORIENTED TALENTS OF SAFETY PROFESSION IN SIT}

The safety engineering profession must has its own industrial features, otherwise it is hard to has a good prospects in the future[10]. Hence, the safety profession should make a definite training orientation in its future development according to the Shanghai's industrial structures, industrial conditions and demands for safety engineering professionals. The authors studied and discussed mainly from the following aspects. 


\section{A. Orientation of talents training mode}

At present, there are mainly two kinds of talents training modes in safety engineering profession. One is based on the industrial safety. In this mode, the curriculum is mainly about the corresponding industrial foundation, which emphasizes the cultivation of students' industrial basic knowledge. The other training mode is based on the general safety. In this mode, the curriculum is mainly on the general safety, backed up by certain industrial safety courses. It cuts both ways to use the above two cultivation modes. Now the safety profession in SIT adapts the latter mode, whose defect is that the graduates trained by this mode are difficult to do the job, for lack of the necessary industrial basic knowledge, when work in corresponding industries such as chemical industry and construction business to perform the safety management or safety technique work.

Hence, according to the requirement of the China's Ministry of Education that the local institutions of higher learning should transform the education type, and combining with the orientation of training the applied technique-oriented talent in SIT, the authors make a training mode of "laying equal stress on both general safety knowledge and specific ability", i.e., taking "big city, general safety" as background, relying on two major industries (chemical industry and construction industry), stressing the features of fire protection, training the medium- and high-calibre applied techniqueoriented and management talents with the abilities of design, detection, evaluation, emergency disposition, supervision and management in the field of occupational safety and health.

\section{B. Optimization of professional curriculum system}

Owing to the previous professional training scheme of the safety profession in SIT has not a definite orientation, hence the selection of professional curriculum are random, and the courses are mainly about the basic knowledge of safety engineering discipline. In addition, though the professional production safety courses such as "Construction Safety Engineering", "Construction \& Installation Technology of Building Equipment", "Chemical Process Safety" and "Analysis \& Prevention of Chemical Equipment Accident" and so on were taught, there were lack of corresponding industrial basic courses, which led to the students couldn't understand and grasp the corresponding professional production safety knowledge. Therefore, according to the reorientation of the talent training target and training mode of safety profession in SIT, the authors adjusted and optimized the previous professional courses system. Firstly, set safety engineering special basic courses (e.g.: Principle of Safety Science, Safety System Engineering, Safety Ergonomics, Safety Management Science and Safety Law, et al) and compulsory courses (e.g.: Special Equipment Safety Engineering, Mechanical \& Electrical Safety, Ventilation \& Purification Engineering, Accident Analysis Technology, et al). Secondly, combining with the professional characteristics of SIT, the module elective courses based on the construction and chemical industries were set, among which the Building Module contains the courses of "Introduction to Architecture Engineering", "Construction Safety Engineering" and "Construction \& Installation Technology of Building
Equipment"; the Chemical Module contains the courses of "Elementary Chemical Engineering", "Chemical Safety" and "Safety Technology \& Management of Dangerous Chemicals". The students must choose one of the above two modules to study. Thirdly, in order to stress the features of fire protection, the corresponding courses such as "Control of Fire \& Explosion Disaster", "Building Fire Technology \& Equipment" and the fire design-related basic courses such as "Engineering Thermodynamics \& Heat Transfer", "Fluid Mechanics \& Fluid Machinery" were set. At last, in order to strength the safety professional basic knowledge and the corresponding industrial knowledge, twelve elective courses such as "Safety Information Engineering", "Safety Detection \& Inspection Technology" were offered. The students can choose four courses freedom from the twelve elective courses to study.

Through the adjustment and optimization of the professional course system, the training target and features of safety profession are more clearly, which is not only focus on the safety professional basic knowledge, but also emphasize on certain industrial basic knowledge. And this lays a good foundation for training the applied technique-oriented talents not only with the solid safety professional knowledge, but also with certain industrial basic knowledge.

\section{Reform of the teaching process}

It is well known that the social adaptive capability and practical ability of the safety engineering professionals are the key abilities required by the enterprises under the background of the present economic and social development. But there is still a gap between the requirements of the employer and students' practical ability. Hence, it is important to train and improve the students' practical ability and problem-solving ability during the teaching process. Some reform measures have been proposed as the following:

- Combining the classroom teaching with the on-the-spot teaching. The classroom teaching is conducted by the college teacher, and the on-the-spot teaching is performed by the enterprise experts. In this teaching mode, the college teachers mainly teach the basic knowledge of the safety engineering, while the invited enterprise experts mainly teach the students how to use the safety basic knowledge to avoid or reduce the safety accident by cases analysis and their substantial practical experience, which can enhance the students' application ability of the theoretical knowledge.

- Combining the field practice with the simulated practice. Establish some practice bases, associated laboratories and practical training platforms by the cooperation between school and enterprise, which can provide a better practical environment for the students, and then enhance their practical ability and problemsolving ability.

- In order to ensure the practical teaching quality, the practical teaching program has been adjusted and optimized. The main revised contents are as the following: 1) Cut down some repetitive practical work by integrating the practice in class and the sporadic 
extracurricular practice. For example, some course practices(experiments) were integrated together to form a practical course (i.e., Discipline Basic Experiment), which effectively avoid the phenomenon that some course practices (experiments) were set repetitively in some subjects. So the efficiency of the practical teaching was increased. 2) Extend the teaching time of some extracurricular practices with good effect (e.g.: the practical courses of "Specialized (Productive) Practice", "Discipline \& Professional Experiment" and "Graduation Practice"). But the credit hour of the practical course with bad effect (e.g., "Professional Social Practice") was reduced. 3) Replace some practical courses that are short of aim or repetitive with those better suit the training target of safety engineering profession in SIT. Through the above adjustment and optimization, the practical ability and the problem-solving ability of the students will be improved greatly.

\section{Teaching staff construction}

Training applied technique-oriented talents requires the teaching staff with solid theoretical knowledge and abundant practical experience. At present, whether the quantity or the practical experience of the safety teachers in SIT are far from meeting the requirements. Especially, the lack of the safety experts with high level hampers the development of the safety profession. Therefore, teaching staff construction is urgently required. The authors consider that the teaching staff construction should be performed as the following aspects:

- Dispatch present professional teachers to the corresponding enterprises and institutions to study the practical skills and directly take part in the various safety practical activities, which can increase their practical experience and make them obtain much more practical knowledge on safety. The professional teachers experienced these exercises can make the classroom teaching combine with the practices more closely, which can improve the students' learning interest.

- Encourage present professional teachers to register for the examination of Certified Safety Engineer, Certified Safety Assessment Engineer and Certified Fire Engineer, and get the corresponding qualification.

- Increase the number of the part-time teachers. Introduce more enterprise experts with abundant practical experience to the teaching staff to take part in the classroom teaching, practical teaching and the graduation thesis link, which can enhance the practical teaching effect and promote the quality of the applied technique-oriented talents

- Introduce some famous safety experts with high level as possible as we can to promote the further development of safety profession in SIT.

\section{CONCLUSIONS}

According to the characteristics of the safety engineering discipline and the investigation results that made on some corresponding enterprises and public institutions in Shanghai, combining with the school-running orientation of SIT and the problems and drawbacks existed in the safety engineering profession of SIT, the training target and model of applied technique-oriented talents has been clearly claimed, the professional curriculum system of safety profession has been adjusted and optimized. At the same time, the reform measures on teaching process and construction of teaching staff have been proposed.

Through the study, the talent training program of safety engineering profession in SIT will be more targeted and better meet the need of economic and social development for talents with applied technique of safety engineering profession in Shanghai. The results of some partly-done work revealed that this reform has produced certain desired effect. And this focused training mode of the applied technique-oriented talents can be regarded as an reference for other professions to cultivate the applied technique-oriented personnel.

\section{REFERENCES}

[1] H.Y. Niu, R.Y. Zhou, H.Q. Wang, et al. Quality education construction of innovative talents under new situation of the first grade discipline of safety science and engineering[A]. The 23th academic session of Safety Engineering Profession in Chinese university, namely the essays of the 5th education seminar of master in engineering of Chinese Safety Engineering field $[\mathrm{C}]$. Xi'an: Xi'an University of Science and Technology, 2011: 35-38.

[2] K. Wang, S. Li, X. Pan, et al. Analysis on current situations of the development for higher education of safety engineering discipline in China[J]. Journal of Safety Science and Technology, 2012, 8(5): 163168.

[3] J.C. Xu, L. Ma and J. Deng. Research on training mode on persons with technique of safety engineering profession[J]. Journal of Liaoning Technical University, 2003, 22(4): 367-369.

[4] P. Lü. Exploration on Reform of Undergraduate Courses of Safety Engineering Discipline[J]. China Safety Science Journal, 2004, 14(11): 69-72.

[5] Q.J. Yu. Relevant Problems of Safety Engineering Disciplinary Education in China[J]. China Safety Science Journal, 2005, 15(9): 42-44.

[6] H.P. Liu, P. Zhu, Z.R. Liu. Study on teaching material systems for bilingual teaching of chemical process safety[J]. Journal of Safety Science and Technology, 2012, 8(7): 204-208.

[7] H. Hu, C.N. Yi, K.B. Liao, et al. A Study on Practical Teaching Reform of Safety Engineering Major[J]. The Science Education Article Collects, 2013, 253: 80-82

[8] H.P. Jiang, W.Y. Wu, H.Y. He. Penetrating practice and inventiveness in traffic safety engineering education[J]. Journal of Tianjin University of Technology and Education, 2007, 17(3): 49-51.

[9] C.M. Yuan, Z.W. Xie. Discussion on higher education mode of safety engineering professional[J]. Journal of Safety and Environment, 2006, 6 (Suppl.): 35-37. 